\title{
Analysis of Temporal Signals of Climate
}

\section{Peter Stallinga, Igor Khmelinskii}

FCT and CEOT, University of the Algarve, Faro, Portugal

Correspondence to: Peter Stallinga, peter.stallinga@gmail.com

Keywords: Climate Change, Signal Analysis, Cause-Effect, Pinatubo Eruption

Received: July 23, $2018 \quad$ Accepted: October 13, $2018 \quad$ Published: October 16, 2018

Copyright $\odot 2018$ by authors and Scientific Research Publishing Inc.

This work is licensed under the Creative Commons Attribution International License (CC BY 4.0).

http://creativecommons.org/licenses/by/4.0/

\section{(c) $\underset{\mathrm{BY}}{\mathrm{BY}}$ Open Access}

\section{ABSTRACT}

The dynamics of carbon dioxide in the atmosphere is analyzed and it is shown that the Pinatubo eruption in 1991 had a noticeable effect on these dynamics. The growth rate slowed down. Moreover, analyzing the year-on-year $\mathrm{CO}_{2}$ growth data, we can see an anthropogenic footprint, possibly due to the burning of fossil fuels. On top of this anthropogenic contribution is a natural contribution that is of similar magnitude, and that closely follows the ocean surface temperature (influenced by ENSO, El Niño Southern Oscillation). This latter fact is consistent with the hypothesis of the correlation of global temperatures and carbon-dioxide in the atmosphere being governed by Henry's Law, in which carbon dioxide variations are the result of, rather than the cause of, temperature changes. This latter being the so-called "greenhouse effect", sometimes mentioned as responsible for (anthropogenic) climate changes, and that cannot explain the observed phenomena described here. Similar conclusions are drawn on monthly data of carbon dioxide and temperature as well.

\section{INTRODUCTION}

The United Nations Climate Change Conferences, Conference of Parties (COP), are yearly conferences held in the framework of the United Nations Framework Convention on Climate Change (UNFCCC). They serve as the formal meeting of the UNFCCC Parties to assess progress in dealing with climate change, and beginning in the mid-1990s, to negotiate the Kyoto Protocol to establish legally binding obligations for developed countries to reduce their greenhouse gas emissions. From 2005, conferences have also served as the "Conference of the Parties Serving as the Meeting of Parties to the Kyoto Protocol" (CMP). From 2011, the meetings have also been used to negotiate the Paris Agreement as part of the Durban platform activities until its conclusion in 2015, which created a general path towards climate action [1].

The first UN Climate Change Conference was held in 1995 in Berlin. Then there were many more. The first thing we notice on this list is that this series of conferences, COP, perfectly follows the Law of Angus, also called Angus First Law [2]: "All human organizations tend to be self-amplifying. There is an 
effect which hamstrings all corporations, even the most effective ones. It is the natural tendency of any organization to become ever more like what it already is. This is called the 'self-amplifying' tendency. 'The longer an organization has spent becoming more as it is already, the stronger is the force to pushing it in the same direction like matter being sucked into a black hole. Eventually it will lose the ability to change at all, without recognizing how it happened"'. The series of conferences is growing and attracts politicians from all over the world. But what is exactly the effect of all these conferences, apart from their enormous carbon-footprints? In Figure 1, we can see the growth of carbon dioxide in the atmosphere as measured at the Mauna Loa measuring station [3]. In the figure also some years are labeled with the venue of the COP conference that was held that year. As seems immediately obvious, the effect of the conferences on the carbon dioxide in the atmosphere is ... exactly zero. They are a waste of money and effort, at least up to this time.

This, however, brings us to the main subject. What is actually governing the carbon dioxide signal? And what is the link to the global temperature of our planet? Are they governed by the greenhouse effect, where $\mathrm{CO}_{2}$ in the atmosphere blocks outgoing radiation, thus heating up our planet? (As first stated by Arrhenius [4] and studied by Callendar [5]). Or are they governed by Henry's Law, where heating of the oceans causes out-gassing of $\mathrm{CO}_{2}$ from them into the atmosphere? These are the key questions that keep many scientists, policy makers and society at large busy. We will try to analyze the signals to draw as much information from them as possible. And will actually give the answer here. The signal data we use are as much public domain as possible, so that people can easily check our analysis and follow our reasoning.

\section{RESULTS AND DISCUSSION}

First we go back to the figure above. Looking at this picture of the contemporary data of carbon dioxide concentrations in the atmosphere, something remarkable strikes us. Something seems to have happened at around 1991. What it is exactly, is not clear from the data, but the growth rate seemed to have suddenly come to a standstill. Some years with nearly zero growth seen as a plateau in the graph. We call this "the Event".

As a first observation for sure it is not the result of the COP conferences, because they started after the Event. Theoretically it is possible that the conferences were convened just because of the change of growth rate (or the cause for it), but we reject this idea as silly. We just mention it here for completeness' sake. A more detailed analysis reveals the origin of the Event.

In a first approach we fit a function of exponential growth to which is added a sinusoidal signal with periodicity of one year,

$$
y(t)=A \exp \left(\frac{t-[1950 \text { year }]}{t_{0}}\right)+B \sin \left(\frac{2 \pi t}{(1 \text { year })}+\varphi_{0}\right)+C,
$$

with $y$ representing the $\mathrm{CO}_{2}$ concentration in the atmosphere (henceforward called $\left[\mathrm{CO}_{2}\right]$ ), $t$ representing time, and $A, B, C, t_{0}$ and $\varphi_{0}$ fitting parameters. Figure 1 shows the fit function and the bottom panel of the figure shows the residuals of the data after subtracting the fit function, $y_{\exp }-y_{\mathrm{th}}$. We again recognize something happened around 1990. The data before the Event are more curved than after the Event, indicating a faster growth rate (smaller $t_{0}$ ), as evidenced by the $\mathrm{V}$-shape of the residuals curve.

This is made clearer in the following figure (Figure 2) where a curve was fit to the data up to 1991, the year of the Event. As can be seen, the theoretical and experimental curves rapidly diverge after the Event, demonstrating their different character. Then the same was done to data after 1994 (fit not shown in the figure). Table 1 summarizes the fitting parameters found. As can be seen, the atmospheric $\left[\mathrm{CO}_{2}\right]$ growth rate dropped significantly-nearly a factor 2-the time scale of exponential growth increased from 32 years to 61 years. Whatever the Event was, it was huge and seems to have had lasting effects on the atmosphere of our planet. However, we will analyze here the data in more suitable ways to reveal more detail. 


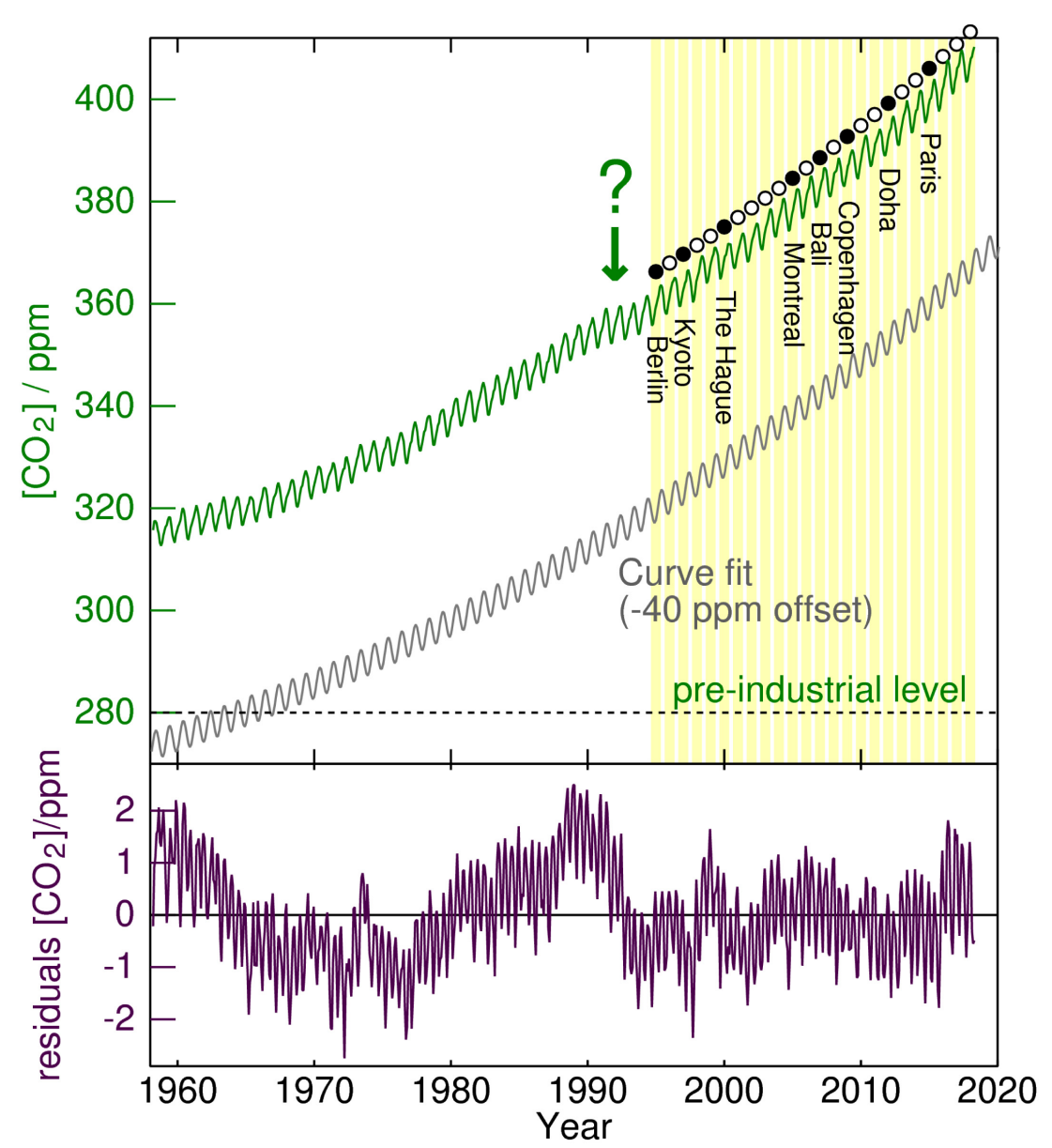

Figure 1. Growth of carbon dioxide in the atmosphere. Years with a COP conference have a yellow bar background and an open circle on top of the curve. Some of these years are labeled with the venue of the conference that year and have a solid dot on top of the curve. The gray curve is a simulation of a function numerically adjusted to the entire data set (for clarity it is offset by $40 \mathrm{ppm}$ ). The bottom panel shows the residuals of the fitting.

Table 1. Fitting parameters obtained for different time intervals.

\begin{tabular}{cccccc}
\hline Parameter & Meaning & full data & before 1991 & after 1994 & (unit) \\
\hline$A$ & Expon. trend & 50.1 & 18.2 & 49.0 & $(\mathrm{ppm})$ \\
$t_{0}$ & Expon. time constant & 61.69 & 32.32 & 60.81 & (year) \\
$B$ & Sine amplitude & 2.85 & 2.75 & 2.96 & $(\mathrm{ppm})$ \\
$C$ & Base line & 256.4 & 291.2 & 257.3 & $(\mathrm{ppm})$ \\
$\varphi_{0}$ & Sine phase & -0.368 & -0.410 & -0.311 & $(\mathrm{rad})$ \\
\hline
\end{tabular}

The next step is finding out what might be the cause for the sudden drastic changes in the atmospheric carbon dioxide. Since the growth of $\mathrm{CO}_{2}$ in the atmosphere is attributed to humans, the first search is for human events. The biggest event in the early 90 s of the previous century is the Gulf War, codenamed 


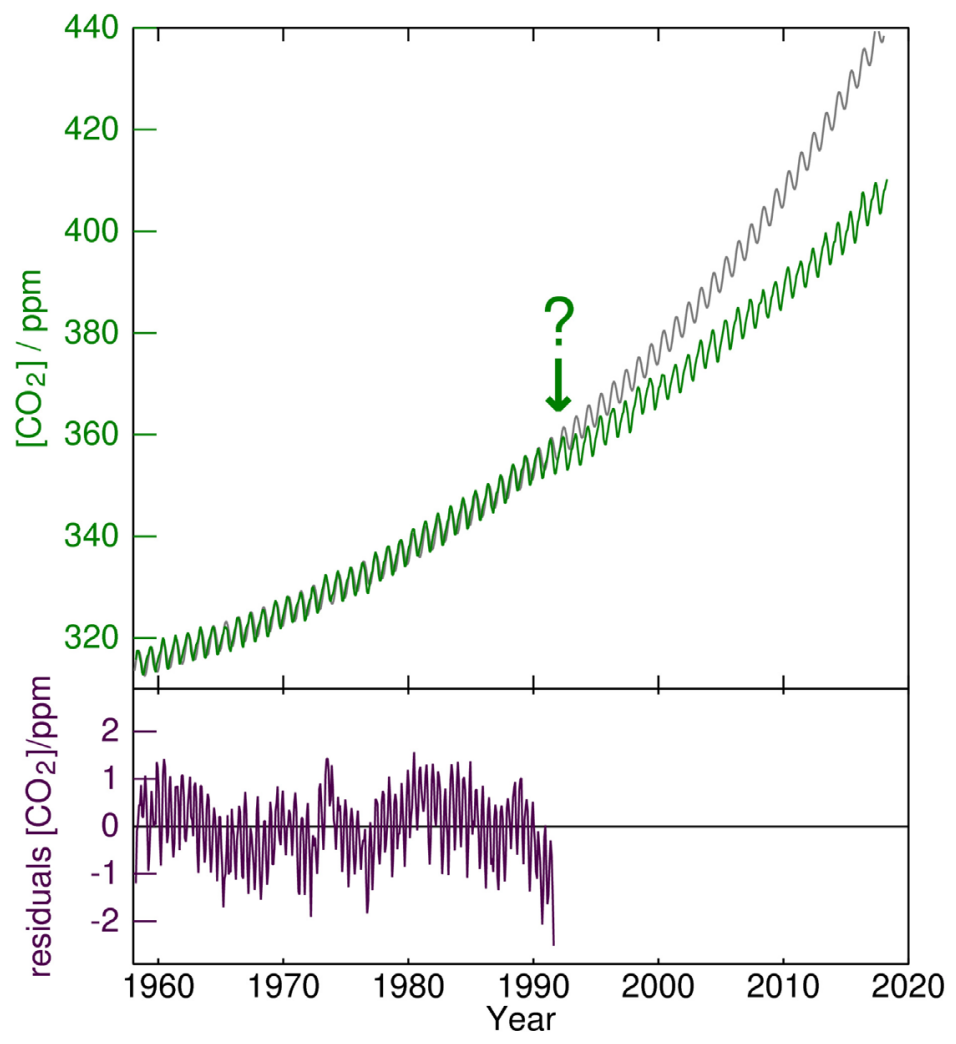

Figure 2. Fitting of data up and including 1990. After this the theoretical and experimental curves rapidly diverge; the residuals are increasingly outside the plotting range after 1992.

Operation Desert Storm. The anthropogenic $\mathrm{CO}_{2}$ emissions are shown in Figure 3 (Source: [6, 7]). These emissions shown in red are composed of all anthropogenic industrial sources: gas, solid, and liquid fossil fuels, cement production, and flaring. We see that the Gulf War had no noticeable impact on the carbon dioxide emissions; the world was business as usual. In fact, we might even recognize a slight increase in the rhythm of human $\mathrm{CO}_{2}$ emission after this period, but this is not really significant. We can also see a more significant thing happening at around 1980, but this cannot be held responsible for change in $\mathrm{CO}_{2}$ rise rate at around 1991. We conclude that there is no human activity responsible for the Event or the slowing down of carbon dioxide growth (increase of the exponential-increase time constant) in the atmosphere.

The same figure also shows the year-to-year increment in carbon dioxide in the atmosphere (see blue curve. Source: NOAA). This is basically the "derivative" (year-to-year changes) of the main curve of Figure 1. The curve is noisier because it contains the highly-regular anthropogenic emissions, as well as the highly-irregular natural effects. Given the fact that $1 \mathrm{ppm} \mathrm{CO}_{2}$ in the atmosphere is equivalent to 7.76 billion tons, we can also show this same curve in tons of carbon dioxide changed in the atmosphere; the figure shows both scales on the right side. What we can immediately see is that about half of all anthropogenic emissions (red curve) are missing from the atmosphere (blue curve). It was injected into the atmosphere, but is not there! Apart from this, the curve fits perfectly; the percentual share of anthropogenic $\mathrm{CO}_{2}$ that is missing from the emissions is constant, independent of amount of $\mathrm{CO}_{2}$ (pumped) in(to) the atmosphere, and independent of time.

What is then remarkable is that natural fluctuations are huge, of the same order of magnitude as the anthropogenic contributions. In total, the natural contribution is negative $50 \%$ of the anthropogenic emissions (i.e., a sink; Sabine et al. estimate 48\% [10]), plus fluctuations, with these fluctuations being of the same order of magnitude as the anthropogenic emissions. 


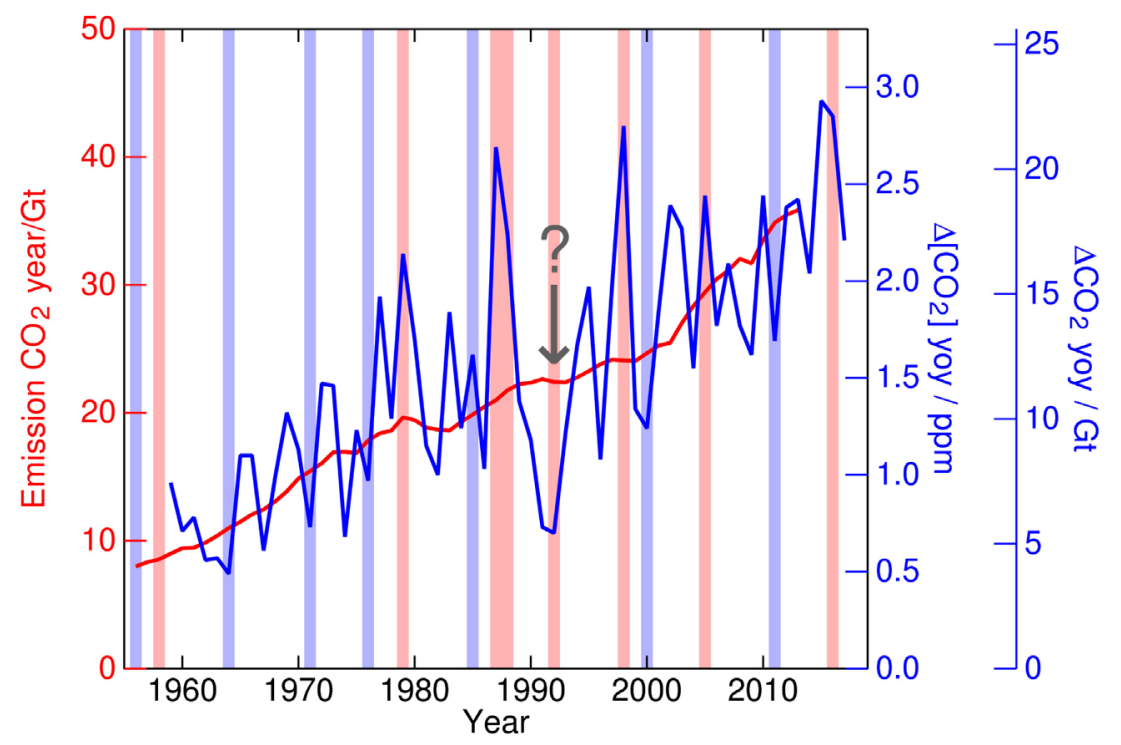

Figure 3. Red: Emission of carbon dioxide in the atmosphere by anthropogenic sources. Source: [6,7]. Blue: Year-on-year (yoy) growth of $\mathrm{CO}_{2}$ in the atmosphere in a scale of concentration ( $\left.\mathrm{ppm}\right)$ and absolute amount (metric gigaton, $\mathrm{Gt}$, of $\mathrm{CO}_{2}$ ). Source: [8]. The vertical bars in light-red and light-blue indicate years of El Niño and La Niña, respectively. Source: [9].

We can get a clear indication of what these natural fluctuations are. In the same figure are indicated the years of El Niños and La Niñas, in light-red and light-blue vertical bars, respectively. As is well known, these are (pseudo)periodic warm and cold phases of ocean surface waters, respectively, in front of the coast of South America that impact the weather patterns of the entire planet. (A phenomenon generally called ENSO: El Niño Southern Oscillation). We can see that there is a very good correlation between years with El Niños that lower and La Niñas that increase nature's capacity to remove carbon dioxide from the atmosphere. An El Niño year adds circa 1 ppm to the atmosphere, a La Niña year removes about the same amount.

We have thus direct proof of Henry's Law that predicts such effects of temperature on the carbon-dioxide content in the atmosphere. Oceans undeniably outgas and absorb $\mathrm{CO}_{2}$ from the atmosphere and they govern the dynamics, the correlation of $\left[\mathrm{CO}_{2}\right]$ with temperature. Note that El Niño is a local phenomenon, but it has an impact on the global temperature of the order $0.1-0.2$ degrees [11]; take for instance the hot El Niño year 1998 that was about half a degree above the trend line [9]. This value is somewhat below, but consistent with earlier values found by us for Henry's Law of about $10 \mathrm{ppm} / \mathrm{K}$ [12] as we will show here.

Note that there is here no question about cause and effect; what came first. Warm water appears at the surface and that causes outgassing of $\mathrm{CO}_{2}$ and simultaneous warming up of the atmosphere. The alternative hypothesis, an inverted cause-and-effect relation with an unidentified source of $\mathrm{CO}_{2}$ causing an appearing of warm waters at the surface of the oceans, can be rejected as the idea is too far-fetched.

We have thus explained the trend (which we attribute to anthropogenic emissions of which directly half disappears in oceans and biosphere), as well as the fluctuations of $\mathrm{CO}_{2}$ growth in the atmosphere. However, we can see that for the year of the unidentified Event (1991), there is a deviation from the modeling. An El Niño year, with relatively warm waters, actually had significantly lower $\mathrm{CO}_{2}$ increase. Instead of a rise of $1 \mathrm{ppm} /$ year above the trend line, it had a drop of $1 \mathrm{ppm} /$ year below the trend line (Figure 3 ).

As said before, this event must have been something natural, but apparently it was not a La Niña. The 
only reasonable natural event we can come up with is the eruption of Pinatubo. The eruption of this volcano in The Philippines was the second-largest terrestrial eruption of the $20^{\text {th }}$ century. It ejected roughly 10 cubic kilometers of magma, and 20 million tons of $\mathrm{SO}_{2}$. It injected more particulate matter into the stratosphere than any eruption since Krakatoa in 1883. Over the following months, the aerosols formed a global layer of sulfuric acid haze. Global temperatures dropped by about 0.5 degrees in the years 1991-93 [13]. The long term effects seem to have been that the growth rate of carbon dioxide in the atmosphere has changed, as evident in Table 1, most probably due to persistent aerosols still remaining in the stratosphere. Some scientists say that the effect disappeared after a couple of years and the planet returned to normal conditions $[14,15]$ which is consistent with the relaxation time of 15 years theoretically predicted by Brasseur and Granier directly after the event [16]. In our data we do not see any signs of that, but we also cannot clearly exclude it. The starting data of Figure 1 seems to show a persistent change in growth rate. The year-to-year-changes data of Figure 3 indeed seem to show that it took only a couple of years to recover.

Having explained the Event, we can go back to the ENSO signal and $\left[\mathrm{CO}_{2}\right]$ increase in the atmosphere. If the greenhouse effect (GHE) hypothesis were correct, in that $\mathrm{CO}_{2}$ causes global temperature change, we do not expect this effect to be immediately visible in the oceans, which'd take a long time to heat up (thousands of years). However, we do see a strong correlation between ocean surface temperature and $\left[\mathrm{CO}_{2}\right]$ in the atmosphere, see Figure 4. If we do insist on attributing the changes of the ocean temperatures to atmospheric $\left[\mathrm{CO}_{2}\right]$ changes, then the question rises, why the anthropogenic emissions do not have any effect on this temperature (so far) and only natural fluctuations do (very rapidly)?

To put it in numbers. We can see in the figure that 1 degree of ocean surface temperature correlates to about $1 \mathrm{ppm}$ of $\mathrm{CO}_{2}$ in the atmosphere. In the framework of AGW (GHE), if humans have increased the concentration from $280 \mathrm{ppm}$ to $400 \mathrm{ppm}\left(\Delta\left[\mathrm{CO}_{2}\right]=120 \mathrm{ppm}\right)$, the planet should have permanently warmed up the oceans by 120 degrees! There is no reason why it shouldn't; it has had more than enough time to relax to this value considering that it can apparently heat up a degree centigrade within the tiny span of a year. In fact, the total multi-century global warming of oceans and atmosphere has been much less than the year-on-year swing of ENSO. How is that possible?!

On the other hand, this fits in the framework of Henry's Law. The value is a little bit low (we'd expect $10 \mathrm{ppm} / \mathrm{K}[12])$. However, don't forget that it may be that it takes time to outgas/ingas the carbon dioxide. We can even make a rough back-of-the-envelope estimation of how long it takes, because the temperature fluctuations are (quasi)periodic. We see about 20 oscillations in the 60 years plotted here, so one oscillation takes circa 3 years. The amplitude in a relaxation model is given by [17]

$$
A=\frac{A_{\max }}{1+\tau / \Delta t}
$$

with the observed $A$ equal to $1 \mathrm{ppm} / \mathrm{K}$, the maximum (full adjustment after infinite time) $A_{\max }=10 \mathrm{ppm} / \mathrm{K}$ (as determined from long-time-span ice-drilling data [12]), and $\Delta t=3$ years, we find a relaxation time of about 30 years, similar to values of $45-60$ years found by Glaser [18]. The associated phase shift is then $85^{\circ}$ [17], nearly a quarter period, which translates into 0.7 years delay between the driving force (temperature oscillations in the oceans) and the resulting changes in the atmosphere. When we look carefully at the figure, we see indeed that the $\mathrm{CO}_{2}$ changes seem to lag behind the temperature changes. It is not clear how much it is, but a value of 0.7 years is consistent with the data.

Finally, we can also look at the monthly data to see if we can extract some information from these too. The above analysis is for the yearly data. Where the temperature anomaly data for the world and all stations are readily available, the global absolute temperature data are more difficult to obtain, but people have been extracting them from the full grid data, such as the one of the University of East Anglia [20]. The monthly data thus found are shown in Figure 5. The red curve shows the average monthly world temperature data (Source: [21] consistent with Figure 7 of [22]) with a sinusoidal fit to them. The green curve is the intra-year $\left[\mathrm{CO}_{2}\right]$ oscillation; the sinusoidal part of the function in Equation (1) with parameters of Table 1. The blue curve shows the effect of the Earth's orbital eccentricity, which makes the distance 


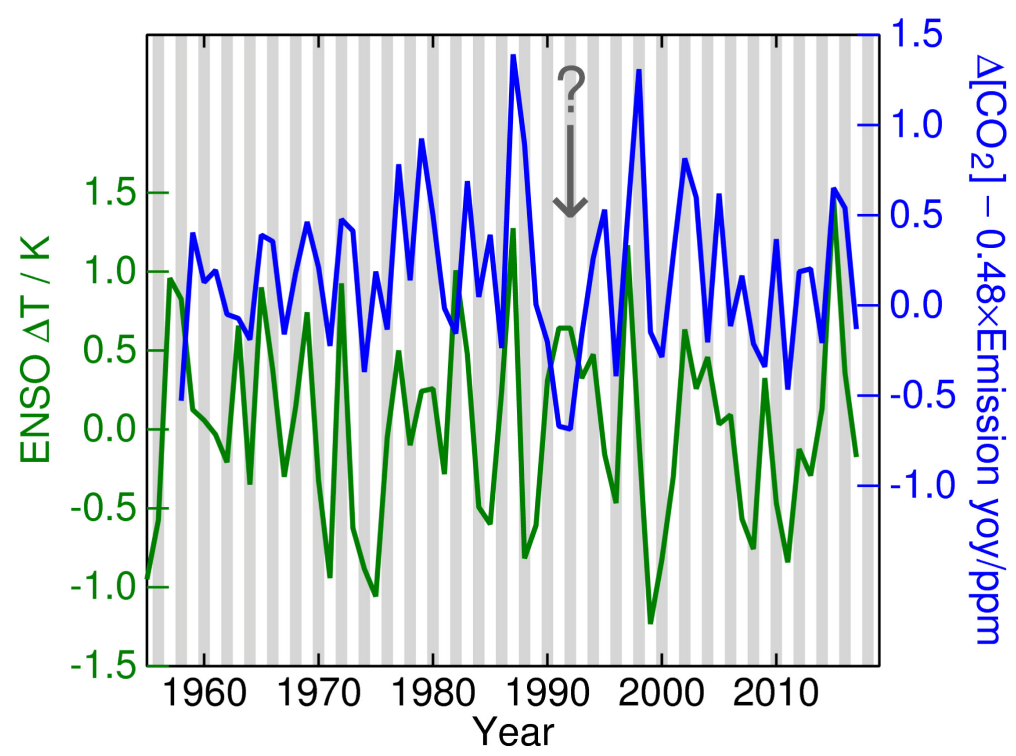

Figure 4. Green: Ocean surface temperature anomaly (ENSO. Source: [19]). Blue: Year-on-year changes in the $\mathrm{CO}_{2}$ concentration in the atmosphere corrected for the anthropogenic emissions (subtracting $48 \%$ of them). A strong correlation is easily visible.

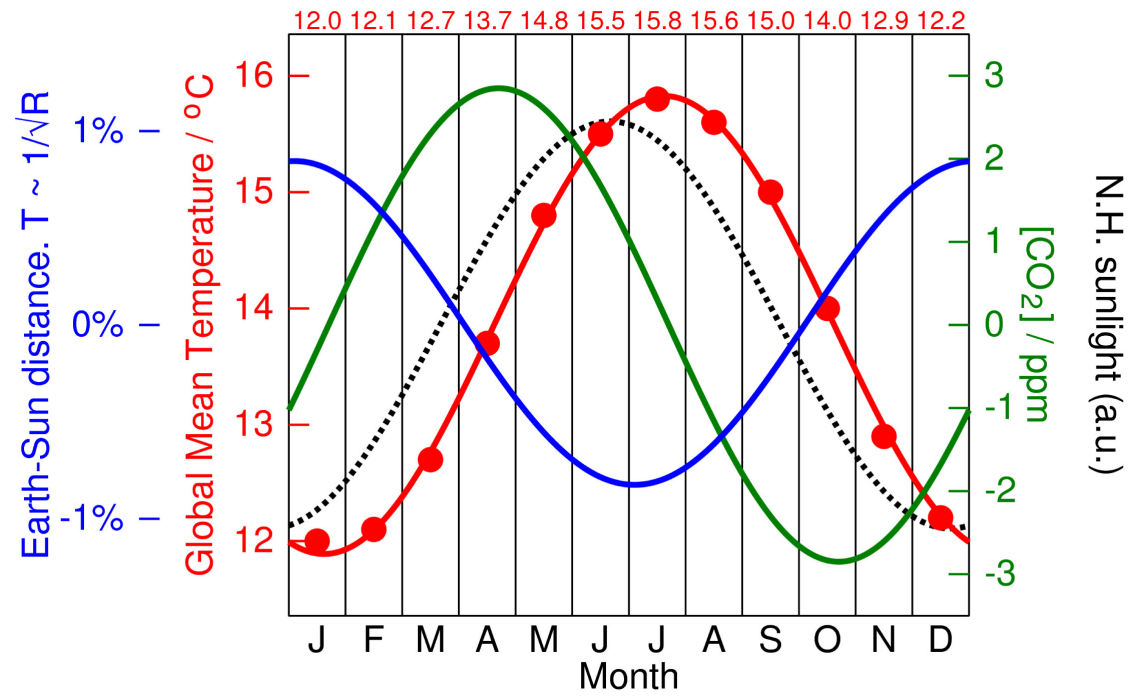

Figure 5. Monthly data. Red: average monthly world temperatures (Source: [21]; original values written on top of the graph) with a sinusoidal fit to the data. Green: intra-year $\left[\mathrm{CO}_{2}\right]$; sinusoidal part of Equation (1) with parameters of Table 1. Blue: Effect of Earth orbital eccentricity.

Earth-Sun (R) oscillate by $1.67 \%$ (from $147.1 \times 10^{6} \mathrm{~km}$ to $152.1 \times 10^{6} \mathrm{~km}$ ) and the received radiation is proportional to $1 / R^{2}$. The emitted radiation is proportional to $T^{4}$, so we expect the temperature $T$ to be proportional to $1 / \sqrt{R}$. This expected-temperature-effect curve is shown in blue (with the orbital oscilla- 
tion simplified as sinusoidal). The figure also shows the light-intensity curve in a typical northern hemisphere moderate zone location (black dashed curve). What matters here is principally the relative phases of the signals. They are summarized in Table 2.

We can see that the $\left[\mathrm{CO}_{2}\right]$ signal (green) is ahead of the global temperature data (red). One might conclude that the temperature swing is thus caused by the carbon dioxide swing. Moreover, the phase shift is very close to the $\pi / 2$ one expects for a simple cause-and-effect relaxation process [17] where the periodicity is much smaller than the relaxation time. However, we do not know anyone in literature who claims that the yearly temperature fluctuations are caused by carbon dioxide oscillations. Moreover,

1) Where do the carbon dioxide oscillations originate in?

2) In this relaxation model, if the correlation is (at least; $A \leq A_{\max }$ ) $4^{\circ} \mathrm{C}$ for $6 \mathrm{ppm}$-the response in a year-and we have increased the concentration in the atmosphere by $120 \mathrm{ppm}$, why did the planet not heat up by (at least) $80^{\circ} \mathrm{C}$ ! The same reasoning that was used for the ENSO ocean temperatures can be applied here. We should be living on molten brimstone. (The biblical reference seems quite adequate, in our opinion).

3) If these $\mathrm{CO}_{2}$ oscillations come from human activity and this activity has changed exponentially in the last decades, the oscillations must have grown in magnitude as well. Figure 6 shows the amplitude of the oscillations for every year of Figure 1, calculated as the April value minus the October value of each year (as these are the months of maximum and minimum value, respectively, as seen in Figure 5). As we can see, while the $\mathrm{CO}_{2}$ in the atmosphere relative to preindustrial levels has risen from $315-280 \mathrm{ppm}$ to 410 - $280 \mathrm{ppm}$ (+270\%; see Figure 1), and the human activity (emissions) has increased from $8 \mathrm{Gt} / \mathrm{yr}$ to 37 Gt/yr (+360\%; see Figure 3), the amplitude of the oscillations has increased relatively much less from about 5.4 to $6.4 \mathrm{ppm}(+19 \%)$. It hints at a natural source for the oscillations rather than an anthropogenic one.

A more reasonable explanation is the following: The global temperature variations are mainly due to effects on the Northern Hemisphere (NH), because that half of the world has more land than the Southern Hemisphere and thus varies more in temperature as a result of sunlight intensity variations. (Water takes much more time to respond because it has convection, distributing the absorbed heat). That is why it is possible that the planet is actually coldest when the sun is closest. The relaxation time of the process of converting solar radiance to temperature on land is a little bit more than a month, creating a delay of about a month in the 12-month-periodic signal; the warmest day is about a month after (NH) summer solstice. Compare the red curve with the black dashed curve.

The biological activity in plants on land is determined by both temperature and luminary intensity. This biological activity is high when these two are high, and basically consists of converting carbon dioxide and water by photosynthesis into biomass. This biological activity is a thermally-activated "Arrhenius" process. We thus see that the carbon dioxide (green curve) declines fastest when temperature (red curve) and light intensity (black curve) are highest. This causes a phase shift of approximately $-\pi / 2$ of $\left[\mathrm{CO}_{2}\right]$ relative to temperature (and light intensity).

Table 2. Relative phase of periodic signals (ex. if the maximum is halfway a year, the phase is $\pi / 2$ ). The day of maximum was calculated from the phase on base of a 365-day year with February having 28 days.

\begin{tabular}{ccc}
\hline Signal & Phase & Approx. day of maximum \\
\hline Sun distance & 1.55 & 3 (3 January) \\
{$\left[\mathrm{CO}_{2}\right]$} & $-0.37^{\star}$ & 113 (23 April) \\
N.H. light intensity & -1.40 & 172 (22 June) \\
Global T & -1.90 & 201 (21 July) \\
\hline
\end{tabular}

*: From Table 1. 


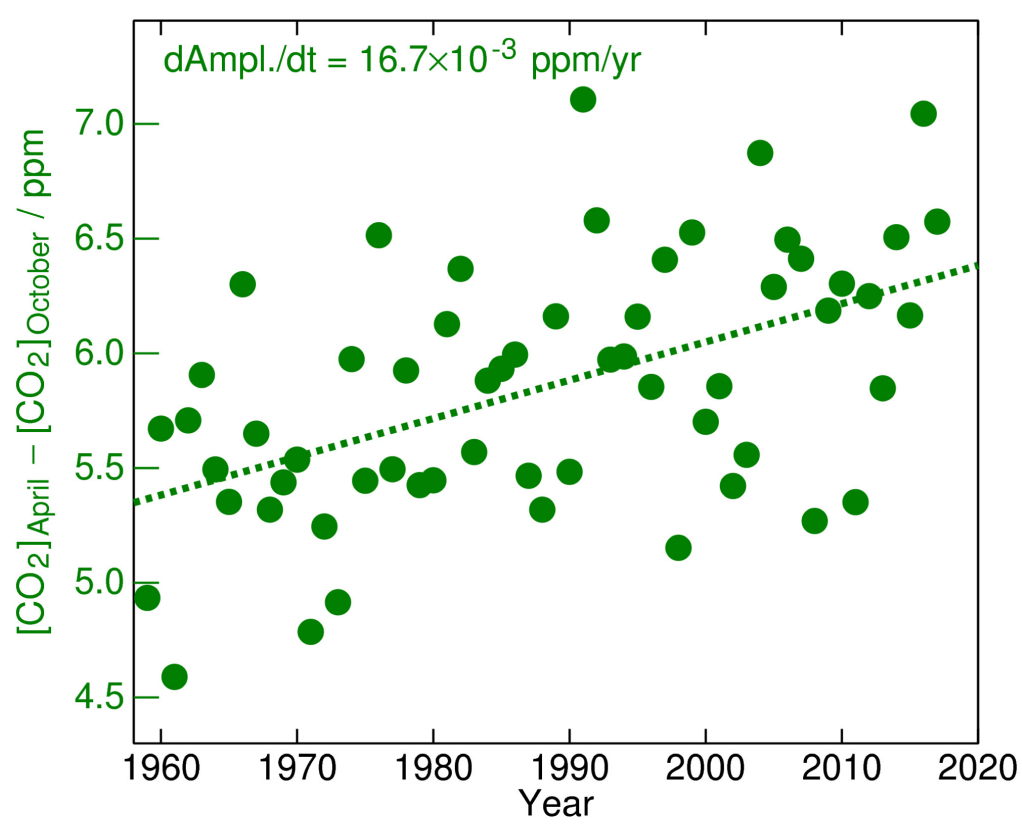

Figure 6. Amplitude of the oscillations of $\left[\mathrm{CO}_{2}\right]$ of Figure 1. It was calculated as the April value of $\left[\mathrm{CO}_{2}\right]$ minus the October value of the same year, corrected for the exponentially growing background (for which the function of Equation (1) and the parameters of Table 1 were used).

What is nice to see is that the biological activity (at least its yearly oscillations) has already increased $19 \%$ since the end of the 1950s, as evidenced by the growth in amplitude of the yearly $\left[\mathrm{CO}_{2}\right]$ oscillations. This can only be considered good news as it indicates an increased food production and global greening of our planet.

\section{CONCLUSIONS}

In conclusion, we have shown here that the dynamics of carbon dioxide in the atmosphere has changed in 1991. These changes we attribute to the eruption of Pinatubo. The year-on-year increase of $\mathrm{CO}_{2}$ in the atmosphere shows a clear contribution of anthropogenic origin. On top of this is a huge natural contribution that can clearly be linked to the ocean surface temperature (through ENSO). This is a very important piece of information in the debate between the two possible hypotheses for explaining the correlation between $\mathrm{CO}_{2}$ concentration in the atmosphere and the global temperature observed in $600 \mathrm{ki}$ loyear historical ice drilling data, the big climate debate, AGW (anthropogenic global warming) through green-house effects (GHE) vs. Henry's Law.

On the one hand, the hypothesis of Henry's Law tells us that $\mathrm{CO}_{2}$ variations in the atmosphere are the result of temperature changes. We had already shown that for historical long-term data Henry's Law is correct [12, 23], as well as for periodic data of a specific meteorological station, De Bilt (Netherlands) [17]. This is directly contradicting the analysis of Al Gore's Inconvenient Truth, but other authors now come to the same conclusions [24]. They, however, insist on attributing a reverse cause-and-effect to contemporary signals, with $\mathrm{CO}_{2}$ changing the temperature [24].

Analyzing the contemporary data of Figure 3, we can conclude that Henry's Law can readily explain this: every time warm water appears at the surface of the oceans, a huge amount of $\mathrm{CO}_{2}$ is released into the atmosphere (or less is absorbed than could be absorbed by cold waters), and in La Niña years when cold water reaches the surface, more $\mathrm{CO}_{2}$ is taken back to the oceans. It is even consistent with the value ob- 
tained on basis of thousands-of-years historical data $(10 \mathrm{ppm} / \mathrm{K}$ [12]). Of course these are slightly different phenomena. In these historical data we see that, every time the temperature changed, for instance by changing solar activity $[25,26]$, it took about 700 years for the ocean waters to adjust to these new meteorological conditions and adjust to the new equilibrium concentration of $\mathrm{CO}_{2}$ in the atmosphere and oceans. Probably governed by mixing of the relevant ocean layers and the time needed to heat up the oceans by heat exchange with the hotter atmosphere and incoming solar radiation. An appearance of warm water and the accompanying dumping of $\mathrm{CO}_{2}$ into the atmosphere (or reduced capacity of absorbing it) is a much faster process; no mixing of layers is needed, nor heating by the atmosphere or the Sun. This explains why we see a large fraction of the total $10 \mathrm{ppm} / \mathrm{K}$ within a single year instead of the tiny 1-year part of a relaxation transient of 700 years. The relaxation time we see in the ENSO events is about 3 decades. This is consistent with the depth and dynamics of the relevant Mixed Layer [27], which is different than the relevant layers in long-term mixing processes.

There is only one instance where the model of Henry's Law fails and that we attribute to the eruption of Pinatubo in 1991 that disturbed the natural rhythm of our planet. This is the Event that is clearly visible in Figure 3 and Figure 4. It disturbed the natural processes of our planet and not even a strong (normally) $\mathrm{CO}_{2}$-liberating El Niño could prevent a disappearance of $\mathrm{CO}_{2}$ from the atmosphere.

On the other hand, the greenhouse effect cannot explain these data. It would need some kind of force that adding minute amounts of the trace gas $\mathrm{CO}_{2}$ into the atmosphere-anyway, where does this $\mathrm{CO}_{2}$ come from?! - would create or change oceanic currents of the magnitude seen in ENSO. That seems too far-fetched to be seriously considered as a valid alternative explanation.

The presented hypothesis is fully consistent with the monthly data analyzed. The periodic warm/cold and light/dark cycles cause a cycle of biological activity that peaks when it is warm and light. The activity consists of taking $\mathrm{CO}_{2}$ out of the atmosphere and converting it to biomass, especially at the Northern Hemisphere that has more landmasses and thus larger temperature oscillations.

We therefore conclude that we can reject the greenhouse effect as significantly climate forcing and thus reject the anthropogenic global warming hypothesis. There is no proof anywhere in any data that adding $\mathrm{CO}_{2}$ to the atmosphere does increase the temperature on this planet substantially. Curbing carbon emissions is therefore rather fruitless and will actually prevent the planet from becoming greener and more productive.

\section{ACKNOWLEDGEMENTS}

This research was paid by no grant. It received no funding whatsoever, apart from our salaries at the university where we work. Nor are we members of any climate committees (political or other) or are we linked to companies or NGOs, financially or otherwise. We are not members of any political party or movement. This is an independent work that does not necessarily represent the opinion of our university or of our government.

\section{CONFLICTS OF INTEREST}

The authors declare no conflicts of interest regarding the publication of this paper.

\section{REFERENCES}

1. United Nations Climate Change Conference. https://en.wikipedia.org/wiki/United_Nations_Climate_Change_conference

2. Whatever Doesn't Make You Stronger Kills You. http://www.cioinsight.com/c/a/Past-Opinions/Whatever-Doesnt-Make-You-Stronger-Kills-You/

3. NOAA. ftp://aftp.cmdl.noaa.gov/products/trends/co2/co2_mm_mlo.txt

4. Arrhenius, S. (1896) On the Influence of Carbonic Acid in the Air upon the Temperature of the Ground. Philo- 
sophical Magazine and Journal of Science, 5th Ser., 41, 237-276.

5. Callendar, G.S. (1938) The Artificial Production of Carbon Dioxide and Its Influence of Temperature. Quarterly Journal of the Royal Meteorological Society, 64, 223-240. https://doi.org/10.1002/qj.49706427503

6. Ritchie, H. and Roser, M. (2018) $\mathrm{CO}_{2}$ and Other Greenhouse Gas Emissions. https://ourworldindata.org/co2-and-other-greenhouse-gas-emissions

7. Boden, T.A., Marland, G. and Andres, R.J. http://cdiac.ess-dive.lbl.gov/ftp/ndp030/global.1751_2014.ems

8. NOAA. ftp://aftp.cmdl.noaa.gov/products/trends/co2/co2_gr_gl.txt

9. Wikipedia. https://en.wikipedia.org/wiki/Global_temperature_record\#/media/File:Satellite_Temperatures.png

10. Sabine, C.L., et al. (2004) The Oceanic Sink for Anthropogenic $\mathrm{CO}_{2}$. Science, 305, 367. https://doi.org/10.1126/science.1097403

11. ClimateBrief. https://www.carbonbrief.org/interactive-much-el-nino-affect-global-temperature

12. Stallinga, P. (2018) Signal Analysis of the Climate: Correlation, Delay and Feedback. Journal of Data Analysis and Information Processing, 6, 30-45. https://doi.org/10.4236/jdaip.2018.62003

13. Wikipedia. https://en.wikipedia.org/wiki/Mount_Pinatubo

14. NASA. https://earthobservatory.nasa.gov/images/1510

15. Hansen, J., Ruedy, R., Sato, M. and Reynolds, R. (1996) Global Surface Air Temperature in 1995: Return to Pre-Pinatubo Level. Geophysical Research Letters, 23, 1665-1668. https://doi.org/10.1029/96GL01040

16. Brasseur, G. and Granier, C. (1992) Mount Pinatubo Aerosols, Chlorofluorocarbons, and Ozone Depletion. Science, 257, 1239-1242. https://doi.org/10.1126/science.257.5074.1239

17. Stallinga, P. and Khmelinskii, I. (2014) Application of Signal Analysis to the Climate. International Scholarly Research Notices, 2014, Article ID: 161530. https://doi.org/10.1155/2014/161530

18. Glaser, K. Global Warming: Correlation between Atmospheric Carbon Dioxide Concentration and Temperature. Roche Colorado Corporation. https://www.lexjansen.com/wuss/2002/WUSS02025.pdf

19. NOAA. http://origin.cpc.ncep.noaa.gov/products/analysis_monitoring/ensostuff/ONI_v5.php

20. Harris, I., Jones, P.D., Osborn, T.J. and Lister, D.H. (2013) Updated High-Resolution Grids of Monthly Climatic Observations-The CRUTS3.10 Dataset. International Journal of Climatology, 34, 623-642. https://doi.org/10.1002/joc.3711

21. junkscience.com. http://junksciencearchive.com/MSU_Temps/Warming_Look.html

22. Jones, P.D., New, M., Parker, D.E., Martin, S. and Rigor, I.G. (1999) Surface Air Temperature and Its Changes over the Past 150 Years. Reviews of Geophysics, 37, 173-199. https://doi.org/10.1029/1999RG900002

23. Stallinga, P. (2010) Dutch. The Myth of Climate Change.

24. Stips, A., Macias, D., Coughlan, C., Garcia-Gorriz, E. and Liang, X.S. (2016) On the Causal Structure between $\mathrm{CO}_{2}$ and Global Temperature. Scientific Reports, 6, Article No. 21691. https://doi.org/10.1038/srep21691

25. Svensmark, H. (1998) Influence of Cosmic Rays on Earth's Climate. Physical Review Letters, 81, 5027-5030. https://doi.org/10.1103/PhysRevLett.81.5027

26. Svensmark, H., Pedersen, J.O.P., Marsh, N.D., Enghoff, M.B. and Uggerhøj, Ul.I. (2007) Experimental Evidence for the Role of Ions in Particle Nucleation under Atmospheric Conditions. Proceedings of the Royal Society A, 463, 385-396. https://doi.org/10.1098/rspa.2006.1773

27. Wikipedia. https://en.wikipedia.org/wiki/Mixed_layer 